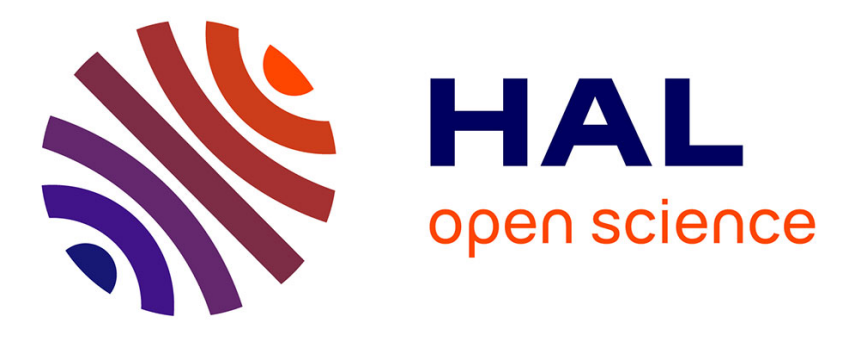

\title{
Preparation of aqueous dispersion of thermoplastic sizing agent for carbon fiber by emulsion/solvent evaporation
}

Isabelle Giraud, Sophie Franceschi-Messant, Emile Perez, Colette Lacabanne, Eric Dantras

\section{To cite this version:}

Isabelle Giraud, Sophie Franceschi-Messant, Emile Perez, Colette Lacabanne, Eric Dantras. Preparation of aqueous dispersion of thermoplastic sizing agent for carbon fiber by emulsion/solvent evaporation. Applied Surface Science, 2013, vol. 266, pp. 94-99. 10.1016/j.apsusc.2012.11.098 . hal00835632

\section{HAL Id: hal-00835632 \\ https://hal.science/hal-00835632}

Submitted on 19 Jun 2013

HAL is a multi-disciplinary open access archive for the deposit and dissemination of scientific research documents, whether they are published or not. The documents may come from teaching and research institutions in France or abroad, or from public or private research centers.
L'archive ouverte pluridisciplinaire $\mathbf{H A L}$, est destinée au dépôt et à la diffusion de documents scientifiques de niveau recherche, publiés ou non, émanant des établissements d'enseignement et de recherche français ou étrangers, des laboratoires publics ou privés. 


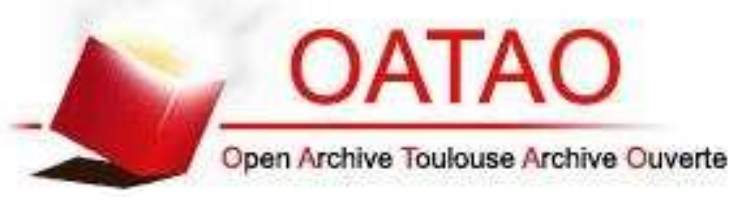

Open Archive Toulouse Archive Ouverte (OATAO)

OATAO is an open access repository that collects the work of Toulouse researchers and makes it freely available over the web where possible.

This is an author-deposited version published in: http://oatao.univ-toulouse.fr/ Eprints ID: 8782

DOI:10.1016/j.apsusc.2012.11.098

Official URL: http://dx.doi.org/10.1016/j.apsusc.2012.11.098

\section{To cite this version:}

Giraud, Isabelle and Franceschi-Messant, Sophie and Perez, Emile and Lacabanne, Colette and Dantras, Eric Preparation of aqueous dispersion of thermoplastic sizing agent for carbon fiber by emulsion/solvent evaporation. (2013) Applied Surface Science, vol. 266 . pp. 94-99. ISSN 0169-4332

Any correspondence concerning this service should be sent to the repository administrator: staff-oatao@inp-toulouse.fr 


\title{
Preparation of aqueous dispersion of thermoplastic sizing agent for carbon fiber by emulsion/solvent evaporation
}

\author{
Isabelle Giraud ${ }^{\mathrm{a}}$, Sophie Franceschi-Messant ${ }^{\mathrm{a}}$, Emile Perez ${ }^{\mathrm{a}, *}$, Colette Lacabanne ${ }^{\mathrm{b}}$, Eric Dantras ${ }^{\mathrm{b}}$ \\ a Laboratoire des I.M.R.C.P., UMR 5623 CNRS, Université Paul Sabatier, 31062 Toulouse Cedex 09, France \\ ${ }^{\mathrm{b}}$ Laboratoire de Physique des Polymères, CIRIMAT, Institut CARNOT, Université Paul Sabatier, 31062 Toulouse Cedex 09, France
}

\begin{abstract}
A B S T R A C T
In this work, different sizing agent aqueous dispersions based on polyetherimide (PEI) were elaborated in order to improve the interface between carbon fibers and a thermoplastic matrix (PEEK). The dispersions were obtained by the emulsion/solvent evaporation technique. To optimize the stability and the film formation on the fibers, two surfactants were tested at different concentrations, with different concentrations of PEI. The dispersions obtained were characterized by dynamic light scattering (DLS) and the stability evaluated by analytical centrifugation (LUMiFuge). The selected dispersions were tested for film formation ability by scanning electron microscopy (SEM), and the sizing performance was assessed by observation of the fiber/matrix interface by SEM. The results revealed that an aqueous dispersion of PEI, stabilized by sodium dodecyl sulfate as the surfactant, led to very stable sizing agent aqueous dispersion
\end{abstract} Sizing

Carbon fibers

Composites

Thermoplastic polymer

Aqueous dispersion

Emulsion/solvent evaporation

\section{Introduction}

Carbon fiber is widely used as a reinforcing material in composites, especially in advanced composites [1,2]. As carbon fibers are brittle, many problems, such as filament breakage and fluffing, arise due to mechanical friction during the manufacturing process [3-5]. Therefore, carbon fibers are generally sized or coated by a sizing layer on the surface, which is usually obtained from a solution or emulsion consisting of polymeric components [6,7]. Sizing eases fiber handling and can also provide a coupling agent for the fiber/matrix bond [8-11]. The nature of the sizing is often kept secret by manufacturers of carbon fibers. However, sizing is chosen according to the nature of the matrix and is generally a pre-polymer or polymer. Most of the composites are made from epoxy resin, and sizing agents are often of the same nature [5,12-14]. This is a problem when the matrix is a high-temperature thermoplastic polymer since the degradation temperature of this type of sizing is around $250^{\circ} \mathrm{C}$ [15]. For polyimides, PEEK and other high-temperature thermoplastic polymers, the functional groups provided by the traditional epoxy-compatible sizing do not react chemically with these polymers and weak interfacial shear strengths result [16]. Moreover, for composites molded with polyimides or PEEK, high processing temperatures during manufacture and continuous use

\footnotetext{
* Corresponding author.

E-mail address: perez@chimie.ups-tlse.fr (E. Perez).
}

in high-temperature environments degrade the epoxy sizing and, consequently, weaken the fiber/matrix interface, producing voids and delaminations [17-19]. All of these observations underline the importance of having sizing that is suitable for high-temperature thermoplastic matrices. From a practical point of view, the sizing formulation should be easy to use, non-toxic and environmentally friendly. In this paper, we report the first example of preparation an aqueous dispersion of a thermoplastic sizing agent for carbon fiber by emulsion/solvent evaporation.

\section{Experimental}

\subsection{Materials}

The polyetherimide PEI (Ultem 1000) was obtained from Sabic ${ }^{\circledR}$. The sodium dodecyl sulfate (SDS) and the chloroform were provided by Sigma-Aldrich, the benzalkonium chloride (BC) was from Fluka $\left(C_{12} 60 \%, C_{14} 40 \%\right.$ ). The AS4 carbon fiber tow, provided by Hexcel, was treated unsized and contained 12,000 fibers. The polyetheretherketone (PEEK) provided by Victrex was a $100 \mu \mathrm{m}$ thick film. The remolding agent was CIREX 041WB from SICOMIN.

\subsection{Preparation of PEI dispersions by emulsion/evaporation}

In order to reduce the toxicity and to respect the environment, organic solvents must be avoided in the final sizing agent formulation. For these reasons, we decided to elaborate aqueous 


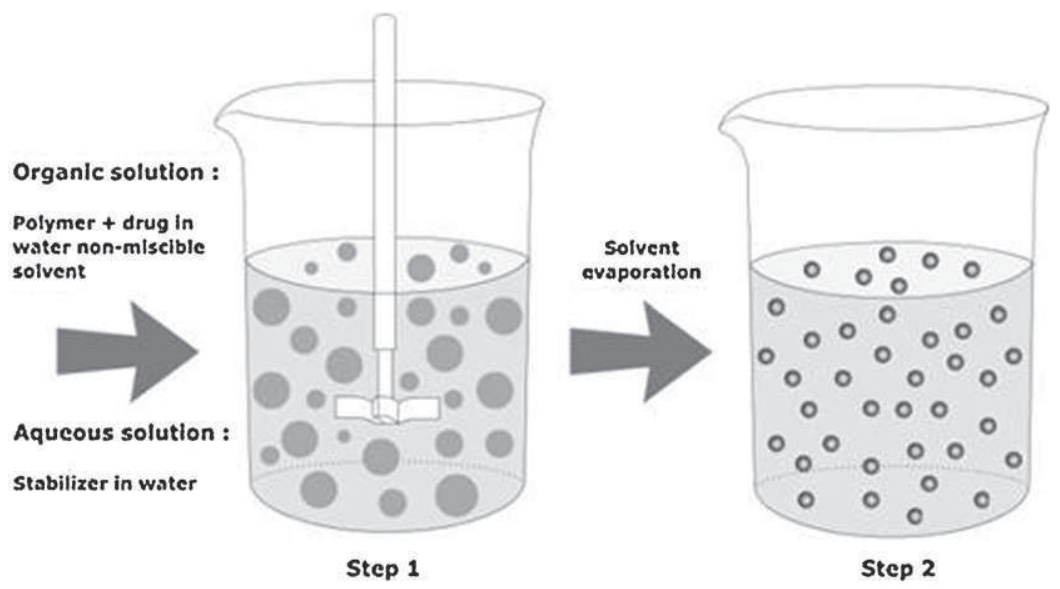

Fig. 1. Schematic representation of the pharmaceutical emulsification/evaporation process.

dispersions. These can be made by a variety of methods [20-23] leading, at the end, to stable hydrophobic particles in water. The preparation process described here was largely inspired by emulsion/solvent evaporation, an encapsulation technique used in the pharmaceutical industry to prepare aqueous dispersions of polymer nanoparticles or microspheres.

Emulsion/solvent evaporation involves a two-step process (Fig. 1): the emulsification of a polymer solution containing the encapsulated substance, followed by particle hardening through solvent evaporation and polymer precipitation. During the water emulsification, the polymer in solution in the volatile, waterimmiscible solvent is broken into microdroplets by the shear stress produced by either a homogenizer or a sonicator in the presence of a surface-active agent until the polymer precipitates [24-27].

This method was used to prepare a stable aqueous dispersion of PEI as the sizing agent. We used two different surfactants, sodium dodecyl sulfate (SDS) and benzalkonium chloride (BC) at different concentrations $(0.3 \%, 0.5 \%$ and $1 \mathrm{wt} \%)$. The final concentrations of PEI were $0.1 \%, 0.3 \%, 0.5 \%$ and $1 \mathrm{wt} \%$. The PEI dispersion at $0.5 \mathrm{wt} \%$ in a $0.5 \mathrm{wt} \%$ surfactant solution was prepared as follows. In a 5-mL flask, $0.1005 \mathrm{~g}$ of PEI was dissolved in $2 \mathrm{~mL}$ of chloroform. This solution was poured into another flask containing $20 \mathrm{~mL}$ of the surfactant solution. The mixture was emulsified by ultrasound shearing (Vibra Cell, Bioblock Scientific $600 \mathrm{~W}, 20 \mathrm{~Hz}$ ). The shearing lasted $5 \mathrm{~min}$ at power 4 . A water bath was used to maintain the solution at room temperature. Then, magnetic stirring of the emulsion at $1200 \mathrm{rpm}$ for $12 \mathrm{~h}$ allowed total evaporation of the chloroform.

\subsection{Characterization of PEI dispersions}

\subsubsection{Particle size analysis}

Dynamic light scattering (DLS) was performed using a Malvern Instruments Nano ZS with a He-Ne laser $(633 \mathrm{~nm})$ at a scattering angle of $173^{\circ}$ and at $25 \pm 1^{\circ} \mathrm{C}$. The hydrodynamic mean diameter of the nanoparticles was determined using the software provided by Malvern Instruments. The Contin model was applied to obtain size data. All the auto-correlation function fits were checked and found to be in accordance with the experimental data. Five measurements were made on each sample with an accuracy of about $2 \mathrm{~nm}$.

\subsubsection{Evaluation of stability using analytical centrifugation}

A separation analyzer (LUMiFuge, L.U.M. Berlin, Germany) was used to determine the separation behavior of dispersions under the influence of various centrifugal forces $(5-1000 \times g)$. This apparatus is based on a low-speed centrifuge combined with an optoelectronic measuring system that records the light transmission over the entire sample cuvette (Fig. 2). The cuvettes containing the suspension are positioned in the horizontal plane on the rotor of the centrifuge. During centrifugation a light source positioned above the rotor emits radiation (near-infrared) onto the sample. Transmitted light is detected by a CCD line sensor below the rotor plane and is analyzed by a microcontroller, which generates a lighttransmission profile of the sample area for every measurement step.

This technique is very appropriate for the study and optimization of very stable aqueous dispersions. The centrifugal force accelerates the destabilization of the dispersion and rapidly determines the shelf life of the dispersion [28]. Moreover, the possibility of studying 8 samples at the same time enables different formulations to be compared immediately $[29,30]$. The dispersions are naturally stable over 6 months so we chose to simulate 3 years of aging. The data acquisition corresponded to 255 profiles recorded every every seconds at $4000 \mathrm{rpm}$. The temperature was $20^{\circ} \mathrm{C}$.

\subsection{Sizing treatment of carbon fiber and composite preparation}

\subsubsection{Sizing of carbon fiber}

Different methods can be used to size carbon fibers, such as electrodeposition [31,32] or electropolymerization [33,34], but the most common is bath coating. We tested the sizing at laboratory scale so, in this case, the most suitable technique was to spray the dispersion directly on to the fiber surface. An unsized fiber tow was strained by a weight to keep it vertical, allowing uniform spraying of the sizing at the fiber surface (Fig. 3). After sizing, the fibers were dried at room temperature.

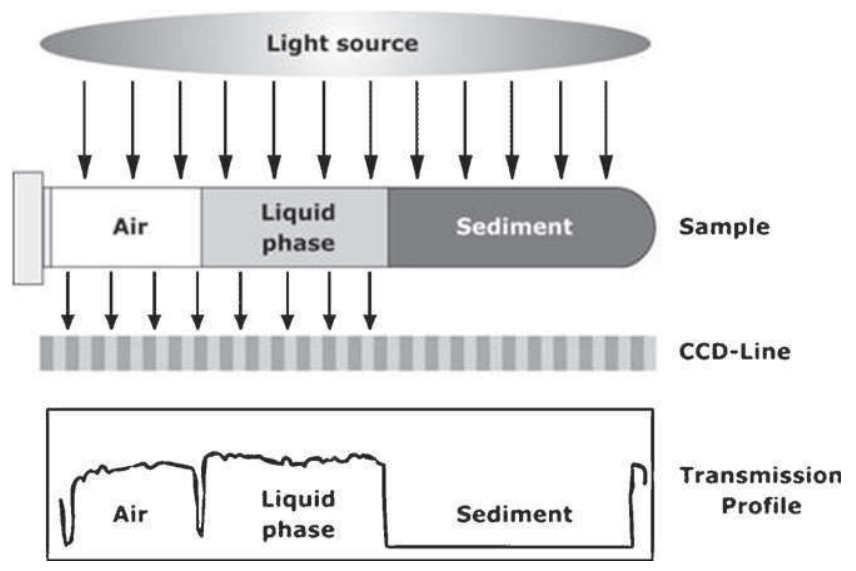

Fig. 2. Measuring principle of the separation analyzer (LUMiFuge). 


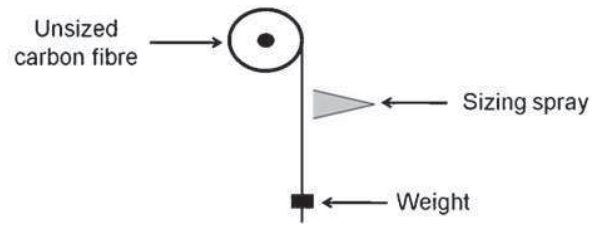

Fig. 3. Schematic representation of the sizing process.

\subsubsection{Composite preparation}

We also prepared PEEK/unidirectional carbon fiber samples at laboratory scale. The samples were prepared by hot press molding. The press used was a Carver $4128 \mathrm{CE}$ equipped with heating plates. The processing took place in several steps. The sample was first prepared, then molded in the hot press and finally cooled and remolded. In order to keep all the carbon fibers in the same direction during the different steps, the strands of carbon fiber were inserted in a folded PEEK film (Fig. 4).

The sample was then placed in an aluminum mold previously coated with the remolding agent. Then the mold was placed between the two plates, previously heated to $400^{\circ} \mathrm{C}$, and kept in contact for 15 min to allow the PEEK to melt uniformly. $6 \mathrm{MPa}$ of pressure was then applied for $30 \mathrm{~s}$ to let the PEEK impregnate the fibers. Finally, the sample was air cooled and remolded at room temperature. The final sample contained $30 \mathrm{wt} \%$ of carbon fibers.

\subsection{Characterization of PEI films and composite}

\subsubsection{Scanning electron microscopy (SEM) analysis}

The different samples were examined using a scanning electron microscope (JEOL JSM 6700F) with an accelerating voltage of $5 \mathrm{kV}$. The films obtained after natural drying at room temperature were mounted on aluminum stubs and sputter coated with gold. The composites were freeze fractured in order to observe the rupture faces.

\section{Results and discussion}

\subsection{Sizing agent formulation}

\subsubsection{Stability study}

We selected PEI as the sizing agent because it is a thermoplastic polymer with high heat resistance [35], miscible with polyetheretherketone (PEEK) [36], and soluble in chlorinated solvents like chloroform. Several factors influence the stability of the dispersion, such as the nature and the amount of surfactant. Usually, the choice of surfactant depends on the nature of the particles and, in particular, their surface charge. Since PEI has no special charge, the surfactant can be anionic or cationic. It is also important

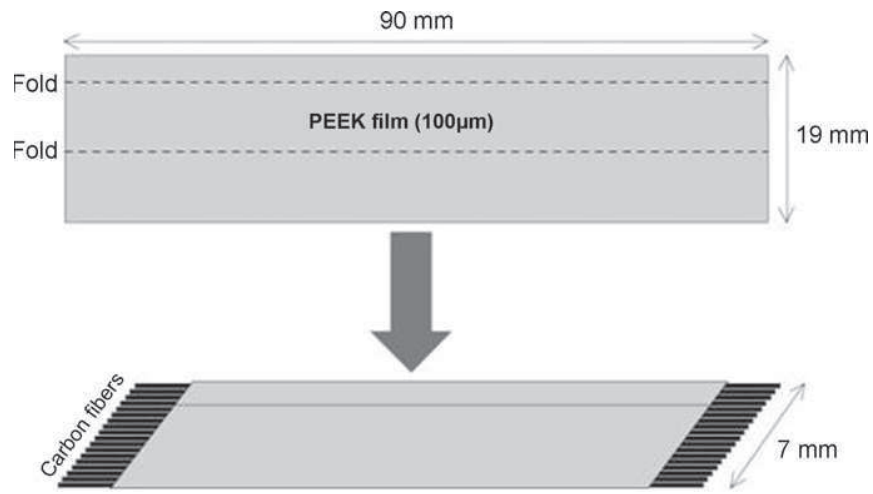

Fig. 4. Scheme of the sample preparation.

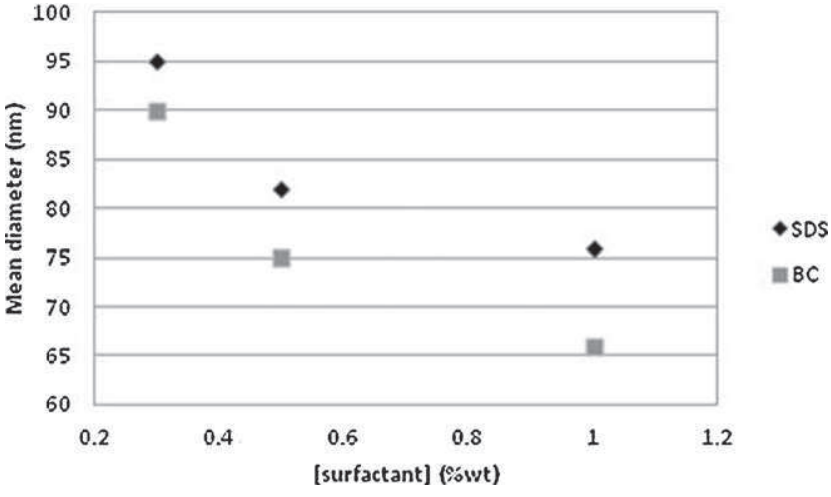

Fig. 5. Influence of the nature and concentration of the surfactant on the mean particle diameter $([\mathrm{PEI}]=0.5 \mathrm{wt} \%)$.

to determine the right quantity of surfactant to maintain a stable dispersion. PEI concentration is also an important parameter. The emulsion/evaporation method is not suitable for the preparation of concentrated dispersions but, in the case of sizing, this is not a limitation because the concentration of polymer does not exceed $1 \mathrm{wt} \%[37,38]$.

First, we studied the influence of the nature and the concentration of the surfactant, and also the influence of the PEI concentration on the characteristics of the sizing dispersions.

The first parameter to be considered was the particle size as it is well known that the smaller the particles are, the more stable the dispersion will be. Dynamic light scattering measurements (DLS) were performed on all the dispersions. The influence of the surfactant on the mean diameter of particles can be seen in Fig. 5 .

The mean diameters of the particles were less than $100 \mathrm{~nm}$ and favored stable dispersions. The nature of the surfactant did not have a significant effect on the particle size even though the particles seemed smaller with the BC surfactant. On the other hand, the diameters varied noticeably with the surfactant concentration. The higher the concentration was, the smaller were the particles. At low concentration, there was not enough surfactant to maintain small droplets of chloroform and this determined the final size of the particles. Although the smallest particles were obtained for $1 \mathrm{wt} \%$, the concentration of $0.5 \%$ was preferred in order to minimize the amount of surfactant in the final formulation.

The same study was performed to observe the influence of the PEI concentration (Fig. 6). The particle size increased quite linearly with the concentration for both surfactants but the mean diameter remained under $100 \mathrm{~nm}$. This result was related to several factors. The first was the ratio between the concentration of surfactant and the amount of chloroform phase containing the dissolved PEI [23]. The second was the viscosity of the organic phase [23].

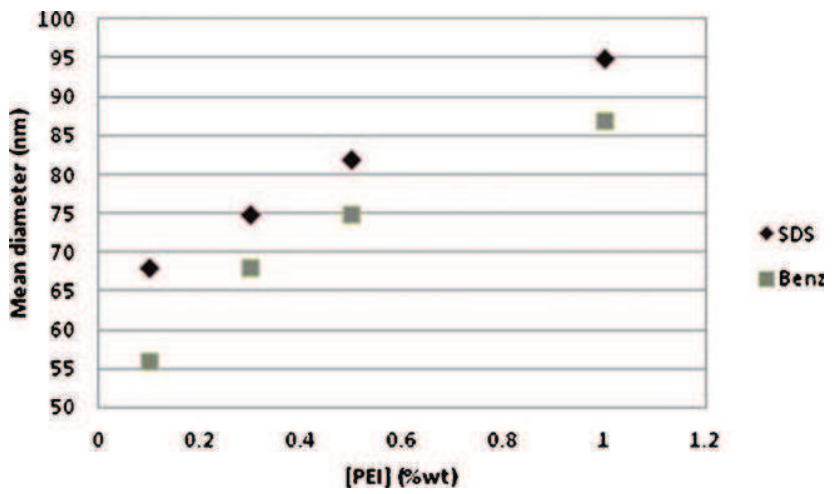

Fig. 6. Influence of PEI concentration on particle diameter ([surfactant $]=0.5 \mathrm{wt} \%$ ). 


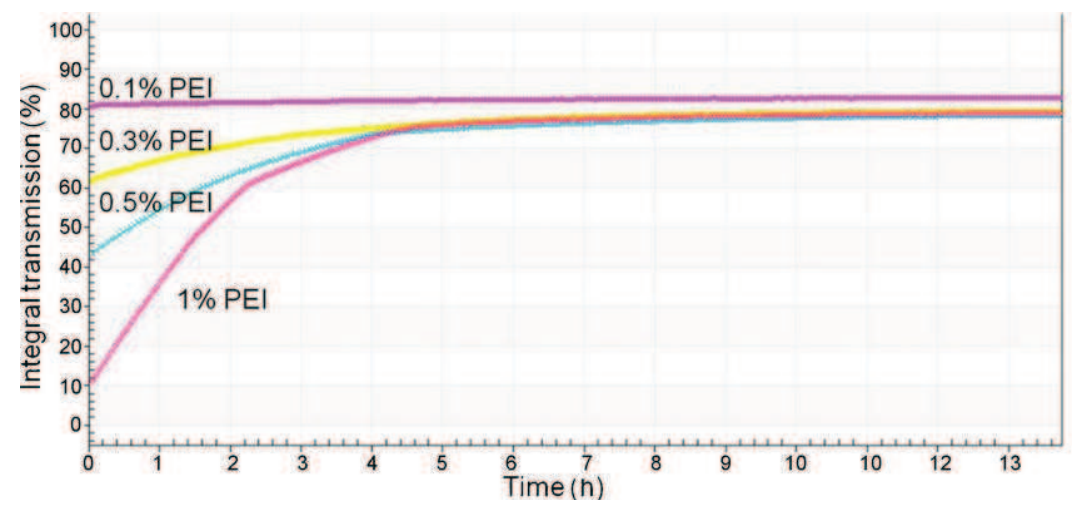

Fig. 7. Effect of the PEI concentration on the clarification kinetics for dispersions at $0.3 \% \mathrm{BC}$.

Increasing the PEI concentration in chloroform increased the viscosity of the solution. Given that the shear forces were always the same, when the concentration of PEI was too high, there was not sufficient enough available to create small droplets of chloroform. The particle size for the lowest concentrations was very small, leading, in principle, to the most stable dispersions. However, for a sizing formulation, the dispersions must have a minimum of $0.5 \%$ or $1 \mathrm{wt} \%$ of PEI.

An interesting stability analysis consisted in determining a destabilization velocity by accelerating the gravitation by centrifugation. This kind of analysis could be performed with the "LUMiFuge" apparatus. This technique is suitable to optimize very stable dispersions (stable for more than 6 months).

From the profiles, an integral transmission was calculated as a function of time. For instance, the influence of the PEI concentration on the stability can be highlighted immediately (Fig. 7).

From this graph, a clarification velocity, corresponding to the slope of the first linear part of the curves, was calculated by the "SEPView" software. The steeper the slope, the more unstable the dispersion. The clarification velocity was calculated for the different dispersions and compared so as to highlight the effect of different parameters.

As shown in Fig. 8, the nature of the surfactant did not have a significant influence on the velocity, except for $0.1 \mathrm{wt} \%$ PEI solution, where BC was less efficient. Considering the surfactant concentration, it seems that, from $0.5 \mathrm{wt} \%$, the stability reaches a plateau. This result indicates that it is not necessary to use more than $0.5 \mathrm{wt} \%$ surfactant solutions to increase the stability.

As expected, the PEI concentration had a major impact on the dispersion stability (Fig. 9). The clarification velocity tripled between $0.5 \%$ and $1 \mathrm{wt} \%$. Although the shelf life cannot be determined directly from the clarification velocity, the real stability

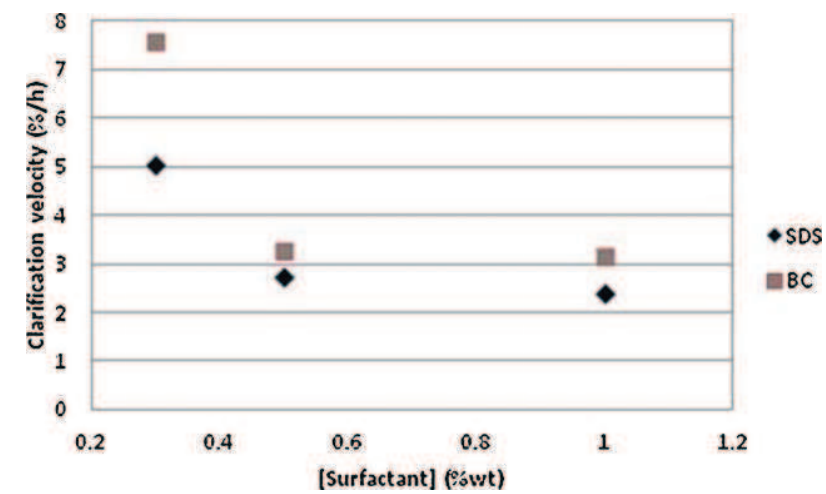

Fig. 8. Influence of the nature and concentration of the surfactant on the clarification velocity $([\mathrm{PEI}]=0.5 \mathrm{wt} \%)$. period extrapolated from the data was estimated to be around 6 months for the $1 \%$ PEI dispersion.

Considering the above results, both the tested surfactants were usable. However, benzalkonium chloride might be more interesting because of its antimicrobial and low foaming properties. Concerning the different concentrations, a good compromise seems to be 0.5 wt\% of surfactant and $0.5 \mathrm{wt} \%$ of PEI.

\subsubsection{Film formation}

For sizing, the coating, and consequently the formation of a film, is a very important property. All the aqueous dispersions prepared were able to form films after water evaporation. To ensure the quality of the film, two chosen dispersions were observed by SEM. One was made with SDS and the other with BC, and both contained $0.5 \mathrm{wt} \%$ of surfactant and $0.5 \mathrm{wt} \%$ of PEI.

The surface aspect of the PEI film obtained with SDS was very homogeneous (Fig. 10). The cracks were due to uncontrolled evaporation. This parameter will need to be taken into account for further applications. The magnification of this film shows partially fused PEI particles (Fig. 11). This observation is typical of latex film formation, and is ideal for a homogeneous coating.

The PEI film formed by the BC dispersion was very different. Fig. 12 is an SEM observation of this film showing a heterogeneous surface. The magnification shows that, in fact, the particles formed agglomerates but did not fuse (Fig. 13). The difference in film formation could be explained by the ability of the surfactant to be drained out of the evaporating film [39-41]. We have to consider the affinity of the surfactant with the surface of the PEI particles to explain this behavior. It seems that, compared to BC, SDS has a lower affinity with the surface of the particles and is mainly drained out of the film, leading to the fusion of the unprotected particles and finally to a homogeneous film.

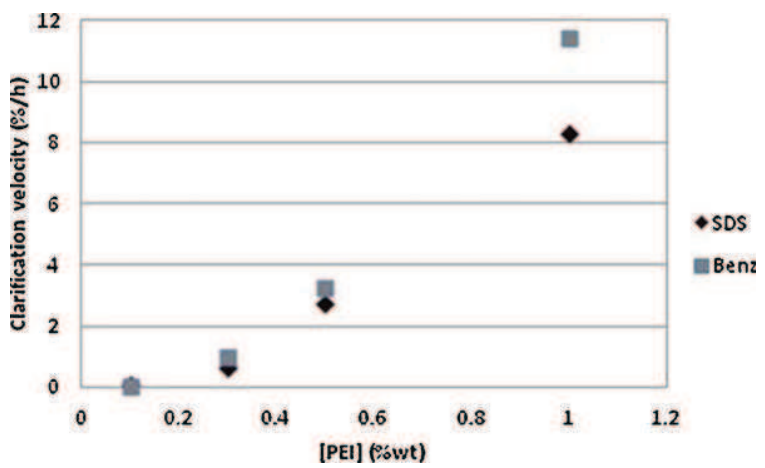

Fig. 9. Influence of the PEI concentration on the clarification velocity ([surfac$\operatorname{tant}]=0.5 \mathrm{wt} \%$ ). 


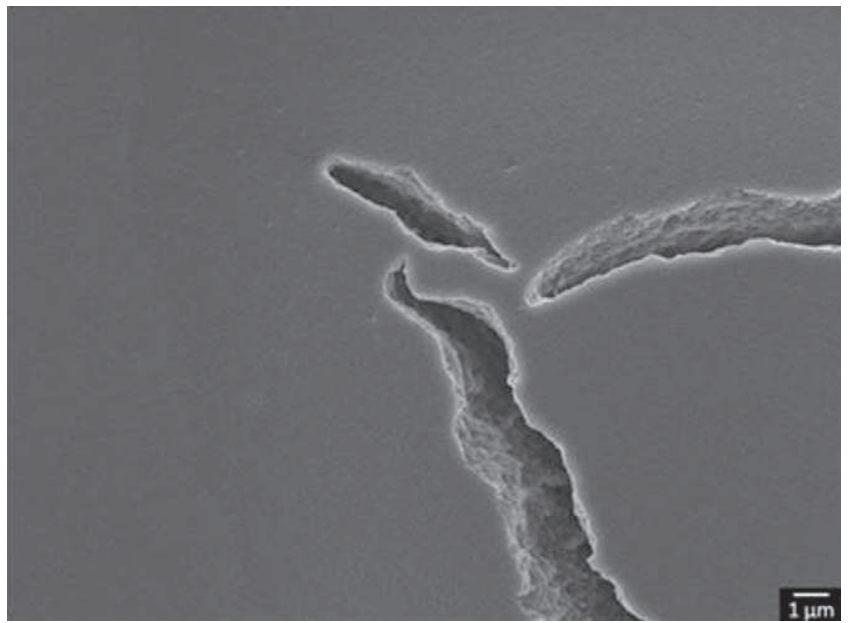

Fig. 10. SEM observation of the film from the SDS dispersion.

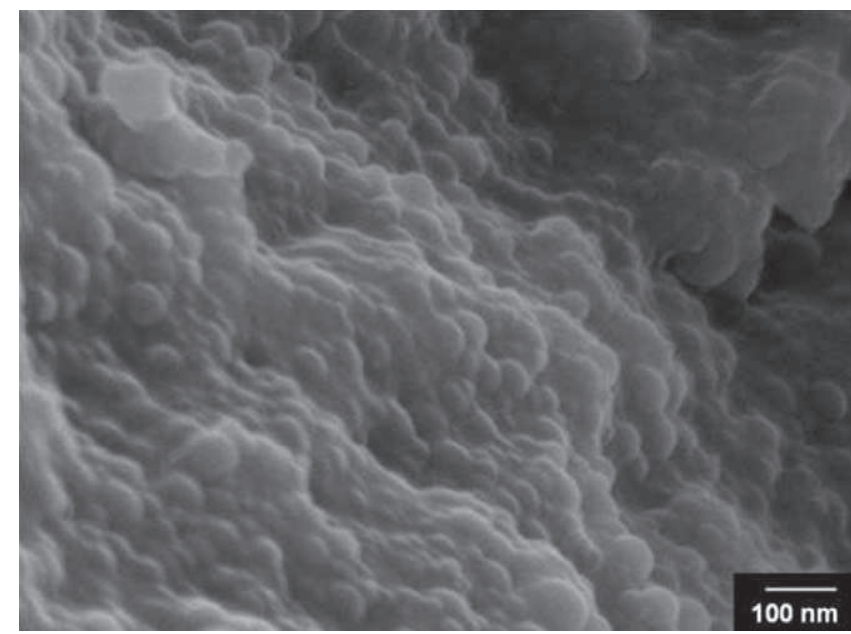

Fig. 11. Magnification of Fig. 10.

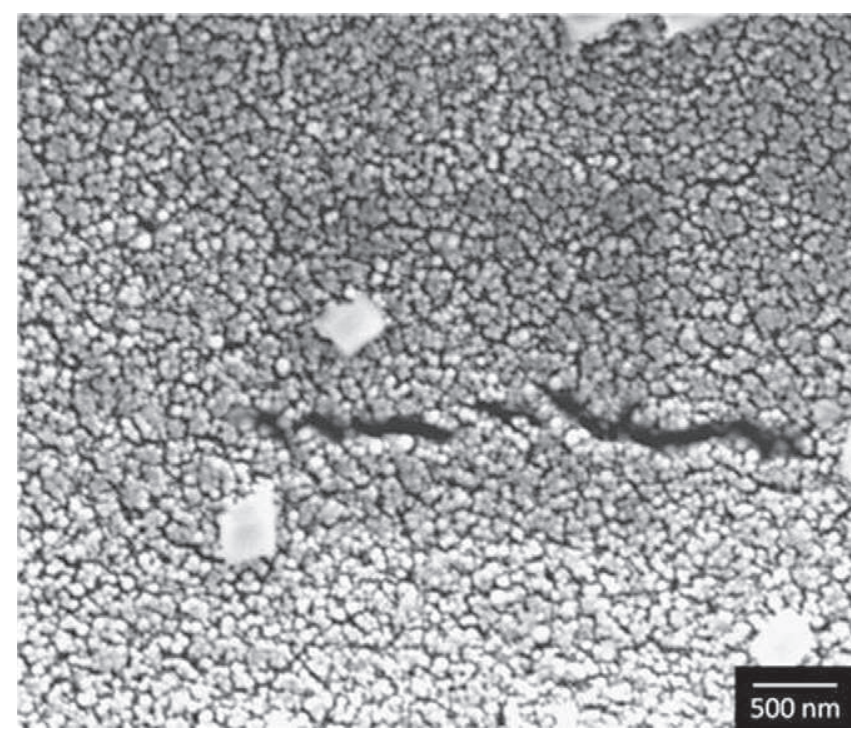

Fig. 12. SEM observation of the film from the BC dispersion.

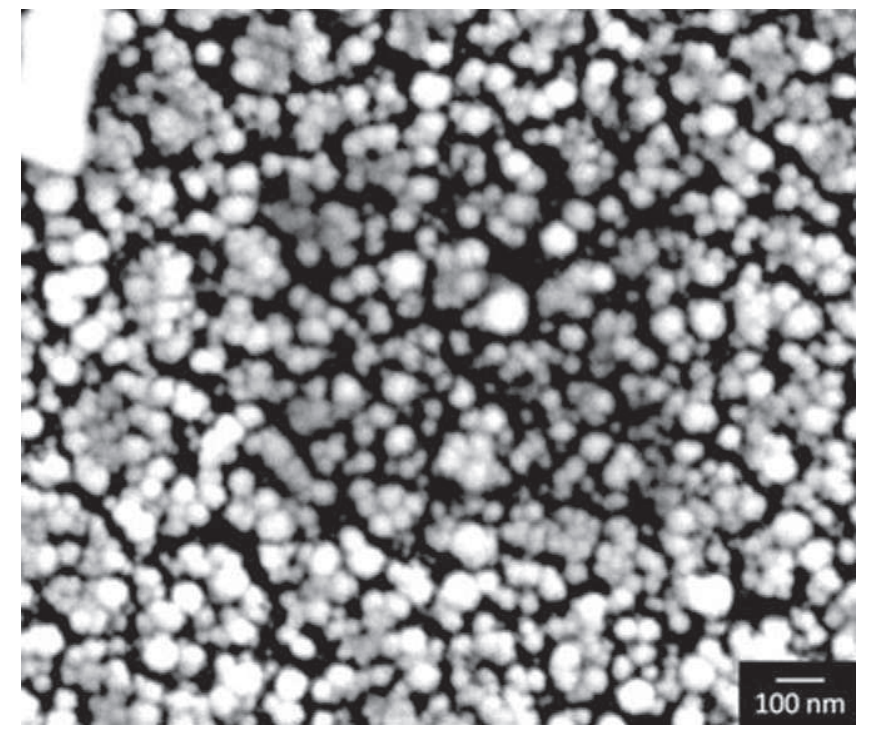

Fig. 13. Magnification of Fig. 12.

Considering these film formation results, the best dispersions for a sizing application seem to be those obtained with SDS as the surfactant. It is very important to obtain a homogeneous coating on the carbon fibers.

\subsection{Sizing evaluation}

The aim of this study was to elaborate a stable aqueous dispersion usable as a thermoplastic sizing formulation for carbon fibers. The sizing has various roles, such as facilitating the handling of fibers and improving the interactions between the matrix and the fibers.

To evaluate the effect of this new sizing, PEEK/carbon fiber composites were made; one with unsized carbon fibers and another with PEI sized carbon fibers. The chosen sizing was the aqueous dispersion with $0.5 \mathrm{wt} \%$ of PEI and $0.5 \mathrm{wt} \%$ of SDS. The best way to highlight the influence of the sizing was to observe the fiber/matrix interface. For that purpose, the composites were freeze fractured transversally and observed by scanning electron microscopy.

Fig. 14 corresponds to an unsized carbon fiber composite and, as we can see, there are voids and no interactions between the PEEK matrix and the carbon fibers. In contrast, the interface between the

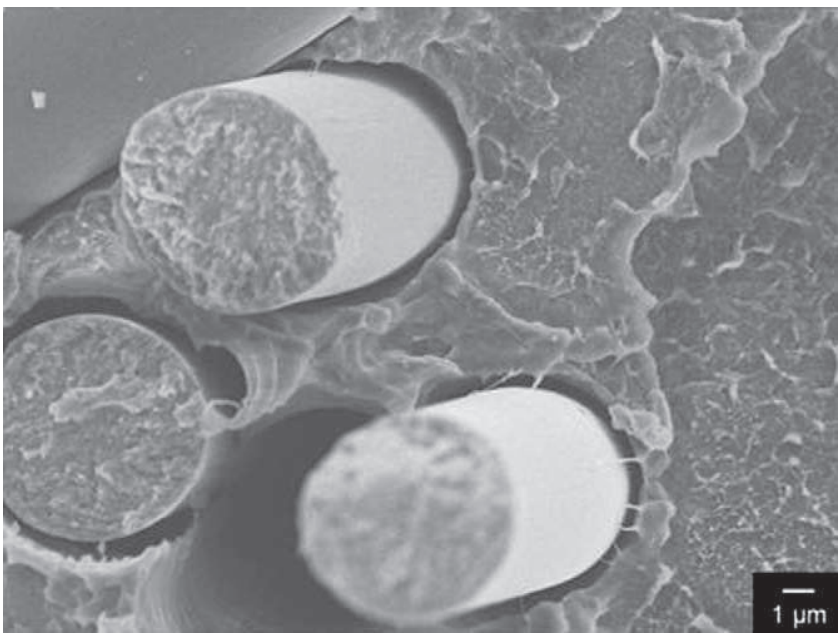

Fig. 14. Unsized carbon fiber composite. 


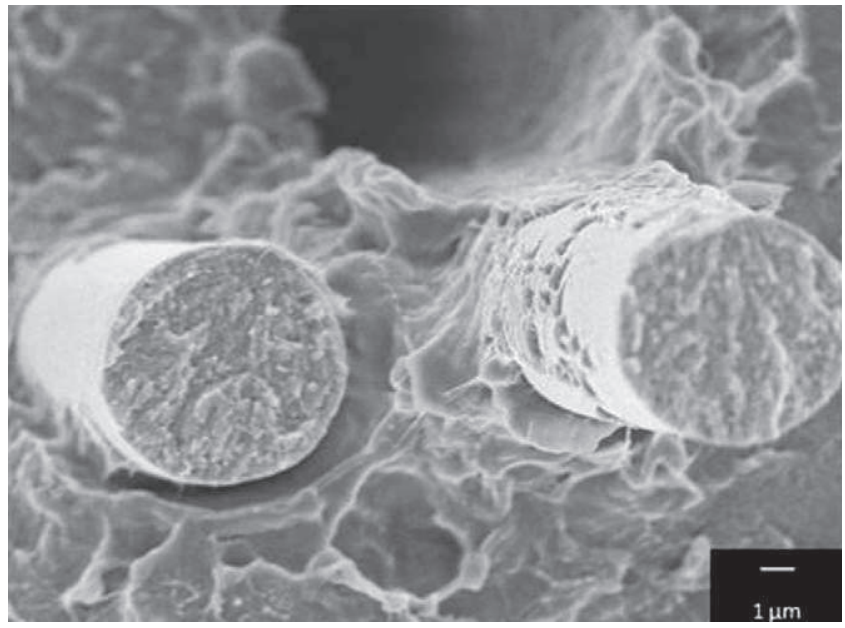

Fig. 15. PEI sized carbon fiber composite.

composite and the PEI sized carbon fibers is continuous (Fig. 15). In this case, there is a real bond between the PEEK and the carbon fibers. These observations confirm not only that the sizing remains during the composite processing but also that the matrix and the carbon fibers are connected by the sizing agent.

\section{Conclusions}

The analyses performed on the different aqueous dispersions revealed that the quantity of particles was a significant factor for stability. The particle size increased greatly with the PEI concentration, which tended to decrease the stability of the dispersion. The LUMiFuge study confirmed this result. The best PEI concentration obtainable by the emulsion/evaporation technique was $0.5 \mathrm{wt} \%$. The dispersions were stable 1 year at $0.5 \mathrm{wt} \%$, nevertheless the dispersion at $1 \mathrm{wt} \%$ remained stable for 3 months. Concerning the nature of the surfactant, benzalkonium and SDS allowed stable dispersions to be obtained. Nevertheless, the benzalkonium dispersion did not form a homogeneous film and so was not suitable for a sizing application. In contrast, with SDS dispersion, the film was really uniform and we observed a coalescence phenomenon typical of latex film formation. The concentration of the surfactant also had an influence on the particle size and stability, and $0.3 \%$ was not enough to obtain a good dispersion. The gain in stability obtained at $1 \%$ did not justify the use of such a concentration considering that there was only $0.5 \mathrm{wt} \%$ of PEI. So the best concentration of surfactant was $0.5 \mathrm{wt} \%$.

Considering all the results, the chosen dispersion for sizing was $0.5 \%$ PEI and $0.5 \%$ SDS. The efficiency of this new sizing agent aqueous dispersion was appreciated through SEM observations, which showed a continuous interface between the carbon fibers and the PEEK matrix.

\section{Acknowledgements}

We thank Mr J.M. Bergerat, AIRBUS Industry, Toulouse France, for useful discussions and advice. The financial support of FUI INMAT2 and AIRBUS is gratefully acknowledged. We also thank $\mathrm{Mr}$ D. Kemmish and Mr A. Wood from Victrex Inc., for their insightful comments and fruitful discussions.

\section{References}

[1] P. Morgan, Carbon Fibers and Their Composites, CRC Press Taylor \& Francis Group, New York, 2005.

[2] D.D.L. Chung, Carbon Fiber Composites, Butterworth-Heinemann, Newton, 1994.

[3] B. Fernandez, A. Arbelaiz, A. Valea, F. Mujika, I. Mondragon, Polymer Composites 25 (2004) 319-330.

[4] W. Chen, Y. Yu, P. Li, C. Wang, T. Zhou, X. Yang, Composites Science and Technology 67 (2007) 2261-2270.

[5] A. Paipetis, C. Galiotis, Composites Part A: Applied Science and Manufacturing 27 (1996) 755-767.

[6] N. Dilsiz, J.P. Wightman, Carbon 37 (1999) 1105-1114.

[7] R.B. Guan, Y.G. Yang, J.T. Zheng, Fiber composites 1 (2002) 23.

[8] T.Q. Li, M.Q. Zhang, H.M. Zeng, Polymer 40 (1999) 4307-4313.

[9] S.-L. Gao, J.-K. Kim, Composites Part A: Applied Science and Manufacturing 32 (2001) 775-785.

[10] L.T. Drzal, M.J. Rich, M.F. Koenig, P.F. Lloyd, The Journal of Adhesion 16 (1983) $133-152$.

[11] Z. Dai, F. Shi, B. Zhang, M. Li, Z. Zhang, Applied Surface Science 257 (2011) 6980-6985.

[12] Z. Dai, B. Zhang, F. Shi, M. Li, Z. Zhang, Y. GU, Applied Surface Science 257 (2011) 8457-8461.

[13] P. Ren, G. Liang, Z. Zhang, Polymer Composites 27 (2006) 591-598.

[14] V.S. Mironov, M. Park, J. Kim, S.H. Lim, C.R. Choe, Journal of Materials Science Letters 20 (2001), 1211-1211.

[15] A. Bledzki, E. Fabrycy, A. Kwasek, Journal of Thermal Analysis and Calorimetry 29 (1984) 989-994.

[16] D.M. Blackketter, D. Upadhyaya, T.R. King, J.A. King, Polymer Composites 14 (1993) 430-436

[17] T.K. O'Brien, Journal of Reinforced Plastics and Composites 7 (1988) 341-359.

[18] P. Davies, W.J. Cantwell, H.H. Kausch, Journal of Materials Science Letters 9 (1990) 1349-1350.

[19] A. Todoroki, H. Kobayashi, Composites Science and Technology 52 (1994) 551-559.

[20] S. Freitas, H.P. Merkle, B. Gander, Journal of Controlled Release 102 (2005) 313-332.

[21] C. Zhang, G. Zhang, V. Ji, H. Liao, S. Costil, C. Coddet, Progress in Organic Coatings 66 (2009) 248-253.

[22] P.R. Nepal, M.-K. Chun, H.-K. Choi, International Journal of Pharmaceutics 341 (2007) 85-90.

[23] M. Li, O. Rouaud, D. Poncelet, International Journal of Pharmaceutics 363 (2008) 26-39.

[24] T.R. Tice, R.M. Gilley, Journal of Controlled Release 2 (1985) 343-352.

[25] K.S. Soppimath, T.M. Aminabhavi, A.R. Kulkarni, W.E. Rudzinski, Journal of Controlled Release 70 (2001) 1-20.

[26] S. Freiberg, X.X. Zhu, International Journal of Pharmaceutics 282 (2004) $1-18$.

[27] Z. El Bahri, J.-L. Taverdet, Journal of Applied Polymer Science 103 (2007) $2742-2751$.

[28] M. Kuentz, D. Röthlisberger, European Journal of Pharmaceutics and Biopharmaceutics 56 (2003) 355-361.

[29] T. Sobische, H. He $\beta, H$. Niebelschütz, U. Schmidt, Colloids and Surfaces A: Physicochemical and Engineering Aspects 162 (2000) 1-14.

[30] T. Sobische, D. Lerche, Colloids and Surfaces A: Physicochemical and Engineering Aspects 331 (2008).

[31] A. Bismarck, A.F. Lee, A.S. Sarac, E. Schulz, K. Wilson, Composites Science and Technology 65 (2005) 1564-1573.

[32] A.S. Sarac, E.A. Parlak, E. Sernath, T. Cakir, Journal of Applied Polymer Science 104 (2007) 238-246.

[33] B. Lin, R. Sureshkumar, J.L. Kardos, Chemical Engineering Science 56 (2001) 6563-6575.

[34] C. Dalmolin, S.C. Canobre, S.R. Biaggio, R.C. Rocha-Filho, N. Bocchi, Journal of Electroanalytical Chemistry 578 (2005) 9-15.

[35] R. Torrecillas, A. Baudry, J. Dufray, B. Mortaigne, Polymer Degradation and Stability 54 (1996) 267-274.

[36] G. Crevecoeur, G. Groeninckx, Macromolecules 24 (1991) 1190-1195.

[37] R.L. Zhang, Y.D. Huang, L. Liu, Y.R. Tang, D. Su, L.W. Xu, Applied Surface Science 257 (2011) 3519-3523.

[38] D.D.L. Chung, Carbon Fiber Composites, Butterworth-Heinemann, Newton, 1994, pp. 91-93.

[39] E. Kientz, Y. Holl, Colloids and Surfaces A: Physicochemical and Engineering Aspects 78 (1993) 255-270.

[40] J. Mallégol, J.-P. Gorce, O. Dupont, C. Jeynes, P.J. McDonald, J.L. Keddie, Langmuir 18 (2002) 4478-4487.

[41] A. Tzitzinou, P.M. Jenneson, A.S. Clough, J.L. Keddie, J.R. Lu, P. Zhdan, K.E. Treacher, R. Satguru, Progress in Organic Coatings 35 (1999) 89-99. 